\title{
Evaluation of the Effectiveness of Continuous Venovenous Hemodiafiltration Applied With Oxiris and AN69 Membranes in Patients With Septic Shock-Related Acute Kidney Injury
}

\section{Cem Kıvılcım Kaçar}

Diyarbakir Gazi Yasargil Egitim ve Arastirma Hastanesi

\section{Osman Uzundere}

Diyarbakir Gazi Yasargil Egitim ve Arastirma Hastanesi

\section{Enver Yüksel}

Diyarbakir Gazi Yasargil Egitim ve Arastirma Hastanesi

\section{Deniz Kandemir}

Diyarbakir Gazi Yasargil Egitim ve Arastirma Hastanesi

\section{Esra Akiz Bıçak}

Diyarbakir Gazi Yasargil Egitim ve Arastirma Hastanesi

Abdulkadir Yektaş ( $\sim$ akyektas@hotmail.com)

Diyarbakir Gazi Yasargil Egitim ve Arastirma Hastanesi https://orcid.org/0000-0003-4400-548X

\section{Research article}

Keywords: Septic shock, Acute kidney injury, Continuous renal replacement therapy, Continuous venovenous hemodiafiltration, AN69, Oxiris

Posted Date: January 22nd, 2020

DOI: https://doi.org/10.21203/rs.2.21569/v1

License: (a) (i) This work is licensed under a Creative Commons Attribution 4.0 International License. Read Full License 


\section{Abstract}

Background and objectives: AN69 and Oxiris are filters used in continuous renal replacement therapy. In this study, we aimed to research the effects of these filters on blood cell counts, blood biochemistry, inflammation indicators, clinical status and mortality of patients diagnosed with septic shock-related acute kidney injury.

Method: Between March 2019 and October 2019, 42 adult patients (Group 1: Oxiris $(n=21)$ or Group 2: AN69 ( $n=21)$ ) with septic shock-related acute kidney injury and received continuous venovenous hemodiafiltration (CVVHDF) in the intensive care unit were included in the study and their results were prospectively observed and compared. The data at the begining of CVVHDF (pre-CVVHDF) and 24 hours after the onset of CVVHDF (post-CVVHDF) were recorded.

Results: In the comparison of the pre- and post-CVVHDF values in Group 1, there was a statistically significant decrease detected in the procalcitonin $(p=0.04)$ and noradrenaline infusion rate $(p=0.02)$ levels. In terms of the other data there was no statistically significant difference between pre- and postCVVHDF values in Group 1. In the comparison of the pre- and post-CVVHDF values in Group 2, there was a statistically significant decrease detected in the urea $(p=0.04)$, platelet count $(p=0.02)$ and procalcitonin $(p=0.002)$ levels. There was no statistically significant difference between pre- and postCVVHDF values in terms of the other data in Group 2. There was no statistically significant difference between the groups in terms of mortality.

Conclusions: CVVHDF with Oxiris filter causes a statistically significant decrease in noradrenaline infusion rate. Therefore, we think that the use of CVVHDF with Oxiris filter applied for septic shock-related acute kidney injury will save us time and increase the improvement in the treatment.

\section{Introduction}

Septic shock is a subset of sepsis with circulatory, cellular and metabolic abnormalities. Patients with septic shock may be clinically defined by the need for vasopressors to maintain mean arterial pressure $\geq 65 \mathrm{mmHg}$ and serum lactate levels> $2 \mathrm{mmol} / \mathrm{L}(>18 \mathrm{mg} / \mathrm{dL}$ ) in the absence of hypovolemia (1).

Lipoteichoic acid (LTA) in the structure of gram-positive bacteria and lipopolysaccharide (LPS) endotoxin- in the structure of gram-negative bacteria are proinflammatory bacterial lipids. These bacterial lipids induce proinflammatory cytokine synthesis by signaling monocytes, macrophages, neutrophils and other immune cell types (2). Proinflammatory cytokines induce a cytokine storm, causing endothelial cell disorder. Large molecules and liquid are extravasated into the interstitium (3). As a result, organ dysfunction develops (4). One of the organ dysfunctions that may develop in sepsis is Acute Kidney Injury (AKI). In septic AKI, microcirculatory disorder develops in renal parenchyma as a result of deregulation of inflammatory mediators, immune cell infiltration and nitric oxide synthase (5). 
Treatment of AKI involves treating the underlying disease and supporting renal function with renal replacement therapy (RRT). However, The Surviving Sepsis Campaign Guidelines (6) contain little explanation regarding AKI treatment.

Many studies, with conflicting results, have evaluated the capacity of extracorporeal devices to adsorb endotoxins and cytokines $(7,8)$, but The Surviving Sepsis Campaign Guidelines (6) have not made any recommendations on the use of blood purification techniques.

The size of the endotoxin molecules is about $10 \mathrm{kDa}$. However, it can form aggregates up to $1,000 \mathrm{kDa}$ consisting of covalently bound lipid and polysaccharide (9). Cytokines are molecules that dissolve in water and are in free form in circulation. Their molecular weight is between 0.5-60 kDa (10). RRT filters are semi-permeable membranes with approximately $35 \mathrm{kDa}$ pores (11). Two of these filters, AN69 (M100, Gambro, France) and Oxiris (Baxter, France), are widely used.

AN69 adsorbs cytokines but does not adsorb endotoxins (12). Oxiris adsorbs endotoxins (negatively charged) thanks to the positive charge on the surface in addition to cytokine elimination (13). Most studies of Oxiris include patients with sepsis/septic shock due to gram-negative bacteria. Because endotoxins are a component of gram-negative bacteria, rather than gram-positive bacteria. However, Oxiris may also be useful in the case of sepsis/septic shock due to gram-positive bacteria, as intestinal hypoperfusion usually causes gram-negative bacteria to pass through the digestive lumen into the blood (14).

We think that the use of Oxiris filter in patients with septic shock-related AKI will improve hemodynamics to save time for treatment, reducing the need for noradrenaline.

In this study, we aimed to research the effects of AN69 and Oxiris membranes on blood cell counts, blood biochemistry, inflammation indicators, clinical conditions and mortality of patients with septic shockrelated AKI.

\section{Methods}

This prospective observational study was performed between March 2019 and October 2019 in the Anesthesiology and Reanimation Intensive Care Unit of the Health Sciences University of Diyarbakır Gazi Yaşargil Training and Research Hospital. Our study protocol was approved by the ethics committee of our hospital (234/2019). This study was conducted in accordance with the 2008 Declaration of Helsinki and written informed consent was obtained from all patients or their relatives. G-Power version 3.1.9.4 (Universität Kiel, Germany) was used to calculate the sample size with reference to the proportions specified in a previous study (4). The minimum number of patients to be included in the study was 42 with a two-tailed alpha error of 0.05 , a power of 0.80 , an allocation ratio of $\mathrm{N} 2$ / $\mathrm{N} 1=1$ and an effect size of 0.8. Forty-two patients with septic shock in our intensive care unit (1) who underwent continuous venovenous hemodiafiltration (CVVHDF) due to AKI (15) were included in the study and the results were compared. 


\section{Inclusion criteria}

- Age $\geq 18$ years

- Presence of septic shock (1)

- Development of AKI (15)

\section{Exclusion criteria}

- Documented Stage 5 chronic kidney disease (glomerular filtration rate (GFR) $<15 \mathrm{~mL} / \mathrm{min} / 1.73$ $\mathrm{m} 2)$

- End-stage renal failure in long-term dialysis

- Patients receiving RRT before admission to the ICU

- Patients with an inferior vena cava collabability index (IVCCI) that cannot be measured or have comorbidities that may affect outcomes (16).

Electrocardiography (ECG), pulse oximetry (SpO2) assessment and continuous invasive arterial pressure measurement after intraarterial cannulation were performed in all patients using the BSM-9101K monitor (Nihon Kohden Europe GmbH, Germany).

For vascular access, a double-lumen hemodialysis catheter (11.5 Fr, Scw medicath, China) was inserted into the femoral or internal jugular vein with ultrasonography (USG) guidance (GE Vivid device, United Medical Instruments, USA). In addition to standard treatment, all patients received CVVHDF for 24 hours using Prismaflex CRRT system (Gambro, Sweden) with the adsorbing Oxiris or AN69 filter. Daily dialysis dose was maintained between 35-45 mL / kg / h, blood flow between 100-150 mL / min, and filtration fraction was between 35-45\%. DIALISAN CVVHD BG 2D (Baxter, Italy) was used as dialysis and postdilution solution. The content of dialysis solution was $\mathrm{Na:} 140, \mathrm{~K}: 2$, Ca: $1.75, \mathrm{Mg}: 0.5, \mathrm{Cl}: 111.5$, HCO3: 32, Lactate: 3, Glucose: $6.1 \mathrm{mmol}$ / I.

For the anticoagulation of the circuit, continuous infusion of nonfractionated heparin was used in patients with hemorrhagic profile at physiological margin, and citrat solution was used in patients whose hemorrhage profile was not at physiological margin and / or who had bleeding risk. Heparin was used with an infusion rate of 5-15 IU / kg / h. The dosage of heparin was set for 45-60 seconds with activated partial thromboplastin time [aPTT] (ACL TOP500 and ACL TOP700, Instrumentation Laboratory, Bedford, MA, USA). Prismocitrate 10/2 (Gambro, Italy), a calcium-free but sterile citrate-containing solution, was infused in pretreatment mode in patients undergoing citrated anticoagulation. Content of prismocitrate was 10/2 Citrate: 10, Na: 136, Cl: 106, Citric acid: 2 mmol / I. In postdilution, $10 \%$ calcium chloride was infused and after filtration was $\mathrm{Ca}++$ 0.6-0.8 meq / $\mathrm{L}$ and arterial $\mathrm{Ca}++1-1.5 \mathrm{meq} / \mathrm{L}$.

The fluid balance of the patients was calculated from the inferior vena cava by USG every 4 hours and IVCCI was calculated to keep the IVCCI within the range of $30-40 \%$ (17). 
The researchers who made the diagnosis, applied the CRTT, calculated the USG and IVCCI, collected and evaluated the results were different. The data were collected from the electronic medical record system and patient files of our institution.

Demographic data of the patients, Acute Physiology and Chronic Health Interrogation (APACHE) II score, number of organs with failure, mortality after ARF, duration of ICU stay, source of sepsis, isolated microorganisms in blood culture, KDIGO stage, the type of filter used (AN69 or Oxiris), anticoagulation method (heparin / citrate) was recorded. Sequential Organ Failure Assessment (SOFA) score were recorded at the beginning of CVVHDF (pre-CVVHDF) and 24 hours after the onset of CVVHDF (postCVVHDF).

Furthermore the values of hemoglobin, hematocrit (BC-6800 auto hematology analyzer, Mindray, China), blood cell count (white blood cells [WBC], platelets: BC-6800 auto hematology analyzer, Mindray, China), blood biochemistry (urea, creatinine, GFR, albumin: c702-502 autoanalyser, Roche, Germany), blood gas (lactate: Rapid Point 500 blood gas analyzer, Siemens, Germany), inflammation indicators (Creactive protein [CRP]: Cobas c702 autoanalyser, Roche, Germany; procalcitonin [PRC]: Cobas e601 and COBAS e602 analyzers, Roche, Germany, erythrocyte sedimentation rate [ESR]: Vision-C automatic ESR analyzer, YHLO Biotech, China) and noradrenaline infusion rate (NIR) were recorded at pre- and postCVVHDF. The efficacy of AN69 or Oxiris filters were evaluated by comparing the parameters at pre- and post-CVVHDF.

While writing the article, necessary checks were made with strobe statement checklist used for observational studies.

\section{Statistical Analysis}

SPSS 16.0 for Windows program was used for statistical analysis. Statistical data were expressed as mean and standard deviation, and categorical data were expressed as frequency and percentage. The comparison of categorical data in the groups was made with chi-square test and the results were given as $\mathrm{n} \%$. The Kolmogorov-Smirnov test was used to determine whether the numerical data matched the normality distribution. Student's T-test was used for the evaluation of the numerical data matching the normal distribution between the groups, and Mann-Whitney $U$ test was used for the non-normal distribution. Paired T-test and Wilcoxon Signed Rank test were used for comparison of two normal distribution measurements. Results regarding numerical data were given as mean \pm standard deviation. $\mathrm{P}$ $<0.05$ was accepted as statistically significant.

\section{Results}

The mean age of the patients included in the study was $61.33 \pm 20.01$; Apache II scores were $29.26 \pm 7.75$ and SOFA 1 scores were $10,07 \pm 2,78$. At least 2 and at most 4 organ failure were detected in the patients included in the study. Fifty percent of the patients were female and $50 \%$ were male. During the study period twenty-five of the patients were died. Mortality rate was $59.5 \%$. Heparin was used as anticoagulant 
in $81 \%(n=34)$ and citrate was used in 19\% $(n=8)$. Twenty-one patients had KDIGO stage 3, 13 had KDIGO stage 2 , and 8 had KDIGO stage 1 . There was no statistically significant difference between the two groups in terms of KDIGO stages. The most common source of sepsis was the lungs (33.3\%). The distribution of the patients in terms of the source of sepsis is shown in Figure 1.

The source of sepsis, reproduction in blood culture and the type of filter used are shown in Table 1. Among the gram-negative bacteria P. aeruginosa was found in the blood culture of 7 patients, A. Baumannii in 7, K. Pneumoniae in 4 and Enterobacter spp. in 3 patients; while among the gram-positive bacteria S. epidermidis was found in the blood culture of 3 patients, S. aureus in 3 and S. hominis ssp hominis in 3 patients (Table 1).

In 21 patients, CVVHDF was performed using Oxiris filter (Group 1) and in 21 patients CVVHDF was performed using AN69 filter (Group 2). When the blood cultures of the patients using Oxiris filter were examined 12 patients had gram-negative, 6 patients had gram-positive bacteria growth and 3 patients had no growth. When the blood cultures of the patients using AN69 filter were examined 11 patients had gram-negative, 6 patients had gram-positive bacteria growth and 4 patients had no growth. There was no statistically significant difference between the groups in terms of gram-negative and gram-positive bacteria growth in blood culture (Table 2).

The comparison of the groups in terms of clinical characteristics and laboratory values is shown in Tables 3 and 4 . There was no statistically significant difference between the groups in terms of clinical features and laboratory values.

In the comparison of the pre- and post-CVVHDF values in Group 1, there was a statistically significant decrease detected in the procalcitonin $(p=0.04)$ and noradrenaline infusion rate $(p=0.02)$ levels. In terms of the other data there was no statistically significant difference between pre- and post-CVVHDF values in Group 1. In the comparison of the pre- and post-CVVHDF values in Group 2, there was a statistically significant decrease detected in the urea $(p=0.04)$, platelet count $(p=0.02)$ and procalcitonin $(p=0.002)$ levels. There was no statistically significant difference between pre- and post-CVVHDF values in terms of the other data in Group 2 (Table 4).

Table 5 shows the comparison of the groups in terms of gender, mortality and anticoagulant used. There was no statistically significant difference between the groups in terms of gender, mortality and anticoagulants used.

\section{Discussion}

In our study, at the end of the CVVHDF for 24 hours we detected that PRC and NIR were reduced in patients using Oxiris filter; urea, platelet count and PRC levels were decreased significantly in patients using AN69 filter. There was no statistically significant difference between the groups in terms of mortality. 
LTA, a cell wall component specific to gram-positive bacteria, is the functional equivalent of LPS, the main cell wall component of gram-negative bacteria (18). LTA and LPS are also called pathogenassociated molecular patterns (PAMPs) and stimulate the natural immune response by binding to pattern recognition receptors (PRRs) such as Toll-like receptors (TLRs) expressed by monocytes, macrophages, neutrophils and other immune cell types. Gram-negative LPS mainly signals through TLR4, while Grampositive LTA can bind to and signal through TLR2. (2). Both of these interactions stimulate the activation of Nuclear Factor kappa B (NF-kB), resulting in transcription and secretion of multiple pro-inflammatory cytokines such as tumor necrosis factor (TNF) - $a$, interleukin (IL) $-1, I L-6$, IL-8 and IL-10 that play important roles in inflammatory diseases such as sepsis $(2,14)$. Damaged host cells express surface damage-associated molecular patterns (DAMPs) such as high-mobility-group-box-1 protein (HMGB1) on their surface. DAMPs can be released into circulation and are recognized by pattern recognition receptors (PRRs). Thus, leukocyte activation and cytokine synthesis are increased, fueling the vicious cycle of uncontrolled immuno-inflammatory process. Excessive release of cytokines in the blood is defined as a "cytokine storm" (14). As a result, sepsis or septic shock develops through vasodilatation, endothelial leakage and organ dysfunction (4). One of the organ dysfunctions in sepsis is AKI. Although the pathophysiological mechanism in septic AKI is not fully understood, it is clear that the inflammatory cascade of sepsis contributes to AKI (19). The basic pathophysiological paradigm correlates septic AKI with decreased global renal blood flow, secondary tubular epithelial cell death, or acute tubular necrosis. The reason for this belief is that AKI is associated with hypoperfusion and shock, and that ischemic damage can lead to intense cell death (eg acute tubular necrosis). However, the importance of ischemiareperfusion is increasing (20).

Septic shock is associated with higher mortality compared to sepsis (1). Septic shock continues to account for $62 \%$ of general deaths and hospital mortality rates are above $40 \%$ (21). Mortality associated with AKI is high (40-60\%) and the short- and long-term outcomes in the form of chronic or end-stage renal disease are devastating (5). AKI develops in more than $45 \%$ of patients with septic shock (21). The mortality rate of our study patients was $59.5 \%$. Considering the fact that our patient group had septic shock-related AKI, our mortality rate was within normal limits. There was no significant difference between the groups in terms of mortality.

When we look at the results of four studies in the literature, which examined a large number of patients with sepsis, the most common source of sepsis was reported to be lungs with varying rates (39-68\%). Although the ranking varies, other common sources of infection are the abdomen (8-22\%), unclear (17$20 \%)$, urinary tract $(9-14 \%)$ and soft tissue $(10 \%)(22-25)$. In our study, the most common source of sepsis in the literature was the lungs (33\%), followed by soft tissue (16\%), unclear (16\%), abdomen (12\%), catheter-related infection $(12 \%)$ and urinary tract $(9 \%)$, respectively.

The Sepsis Occurrence in Acutely III Patients (SOAP) study reported an almost equal prevalence of grampositive and gram-negative bacterial infections in patients with sepsis (24). Although subsequent studies (26) have suggested an increase in the incidence of gram-positive organisms, The 2012 Intensive Care Over Nations (ICON) study has shown that gram-negative bacterial infections are more common in the 
United States than gram-positive bacterial infections (27). In our study, gram-negative bacteria grew more in the blood cultures of the patients than gram-positive bacteria.

In a study of 13796 infected ICU patients published in 2009 S. aureus, Pseudomonas species, Enterobacteriaceae (especially E. coli) and fungi were the most common blood cultures. In this study, Acinetobacter accounted for $9 \%$ of patients with positive blood culture (25). In a review published in 2012 , the most common isolated gram-negative bacteria were E. coli, P. aeruginosa and K. pneumonia; and and the most common gram-positive bacteria were S. aureus, S. pneumonia and Enterococcus spp. in patients with sepsis and septic shock (28). In our study, the most common gram-negative bacteria were $P$. aeruginosa, A. Baumannii, K. Pneumoniae and Enterobacter spp; and the most common gram-positive bacteria were S. epidermidis, S. aureus and S. hominis ssp hominis in the blood culture. Our study was consistent with previous studies in terms of blood culture reproduction. However, $20 \%$ of patients with positive blood culture had acinetobacter reproduction and this rate was higher than previous studies.

Continuous renal replacement therapy (CRRT) with improvement in extracorporeal blood purification techniques and membrane materials are widely used in critical illness (10). The theoretical cut-off for an RRT membrane is about $35 \mathrm{kDa}$. Throughout this membrane, diffusion and convection can take place. Diffusion follows a concentration gradient (as in intermittent hemodialysis) and is an ideal method to remove small ( $<500 \mathrm{Da}$ ) molecules such as creatinine. Convection follows a hydrostatic pressure gradient and is the best method for elimination of medium to large (500 Da to $60 \mathrm{kDa}, 13,750 \mathrm{Da}$ beta-2 microglobulin) and large molecules (60 to $100 \mathrm{kDa}$, eg $70 \mathrm{kDa}$ albumin). In clinical practice, high (60 kDa) or median $(50 \mathrm{kDa})$ cut-off membranes are almost never used because high cut-off membranes may increase the risk of albumin loss (11). Endotoxin molecules have a size of approximately $10 \mathrm{kDa}$, but can form aggregates of up to $1,000 \mathrm{kDa}$ consisting of a covalently bonded lipid and polysaccharide (9). The smaller molecular weight of the cytokines, the more cytokines will be removed in the CRRT. The cutoff value of CRRT was 30-40 kDa, while IL-1 $\beta$ was $17 \mathrm{kDa}$, IL-1RA 15-20 kDa, IL-2 $15 \mathrm{kDa}$, IL-6 $26 \mathrm{kDa}$, IL-8 $8 \mathrm{kDa}$, macrophage migration inhibitory factor (MIF) has a molecular weight of $12.5 \mathrm{kDa}$, IL-10 35$40 \mathrm{kDa}$ and TNF-a51 kDa. Thus, only IL-10 and TNF- $\mathrm{a}$ are outside the threshold of CRRT; all other cytokines can be slowly removed with CRRT. High volume hemofiltration or treatments like the ones with the use of a high cut-off membrane can increase the clearance of inflammatory cytokines but it is still unknown if it could provide benefit to patients (10).

AN69 is a copolymer of hydrophobic acrylonitrile and hydrophilic sodium metahalylsulfonate. As AN69 is negatively charged due to sulfonate groups, the AN69 membrane adsorbs cytokines via ionic bonding between its sulfonate group and the amino group on the surface of a cytokine molecule (12). Oxiris is a high permeability polyacrylonitrile (AN69) based membrane on which a surface treatment of a positively charged polyethylene is added onto the hemofilter. Thanks to this positive charge on the surface of the Oxiris filter - in addition to the bulk cytokine elimination in the mass of the membrane - endotoxin (negatively charged) adsorption takes place (13). In in-vitro studies, Oxiris filter emerges as a hemoperfusion device capable of eliminating both endotoxin and cytokine (29). Endotoxin hemoadsorption can reduce the pathogenic activity and organ dysfunction of endotoxin. Cytokine 
removal by hemofiltration or hemoadsorption can restore the status of immune homeostasis. It is thought that the use of semi-permeable membranes that can provide endotoxin and cytokine elimination is a valuable treatment option in septic shock due to gram-negative bacterial infection (30). Endotoxin may also be present in the circulation due to translocation from the ischemic gut in gram-positive infections (4). Therefore, the use of oxiris in gram-positive sepsis or septic shock may be beneficial (14).

The main finding of our study is that CVVHDF performed with Oxiris filter improves hemodynamics, reduces NIR, is clinically applicable and has no side effects in patients with septic shock-related AKI. Our results confirm the results of some studies in which Oxiris filter was applied in the same patient group. Comparing Oxiris and AN69 filters in patients with septic shock-related AKI Broman et al. found a strong decrease in circulating endotoxin and cytokine levels as a result of CVVHDF treatment with Oxiris filter. This reduction was associated with a favorable hemodynamic effect, such as a faster decrease in blood lactate levels and a decrease in NIR required to maintain mean arterial pressure. There was a blunted cytokine response in both filter groups, but the decrease in TNF-a, IL-6, IL-8, and IFN- $\gamma$ was more outstanding in patients treated with Oxiris than the AN69 filter (4). In the study of Schwindenhammer et al., 31 patients were diagnosed with septic shock between 2014 and 2019 and one of the continuous venovenous hemofiltration (CVVH) or CVVHDF therapies with Oxiris filter was applied. A relative decrease of $88 \%$ was observed in NIR. Lactatemia and pH improved significantly over time (13). In their study on 60 septic patients published in 2019, Turani et al. found that CVVHDF with Oxiris filter improved basic cardiorenal and respiratory parameters and decreased NIR (31).

Shum et al., in a study performed CVVH for 48 hours, found a $37 \%$ reduction in the SOFA score of sepsisrelated AKI patients who underwent Oxiris filter compared to polysulfone-based standard filter (30). In their study published in 2019, Turani et al. found that the SOFA score of 60 septic patients applied CVVHDF with Oxiris filter decreased from $12.4 \pm 2$ to $9 \pm 2$ (31). In our study, no significant decrease was observed in the SOFA score by CVVHDF with Oxiris filter. This is due to the fact that our patients had very severe diseases with high mortality (septic shock-related AKI) and we evaluated the SOFA score after 24 hours of Oxiris administration. Longer CRRT could cause a significant decrease in SOFA score.

In their study on 13 patients with sepsis and multiorgan failure Dahaba AA et al. found that, PRC levels decreased significantly after 12 hours CVVH with AN69 filter (32). Turani et al. in their studies published in 2019, observed a decrease in the PRC level of 60 septic patients who received CVVHDF with Oxiris filter (31). In our study, we found that PRC levels decreased significantly in both groups using Oxiris and AN69 filters after 24 hours of CVVHDF. The cut-off value of AN69 filter is 35-40 kDa (32) and PCT molecular weight is $14.5 \mathrm{kDa}$ (33). We attributed the significant decrease in PCT value after CVVHDF with both filters to the fact that the molecular weight of PCT was considerably lower than the cut-off value.

The limitation of our study is that we evaluate the blood cell counts, blood biochemistry, inflammation indicators, clinical conditions and the mortality results without considering other intermittent conditions after the 24 hours of CVVHDF. We compared the changes that occurred with only one CVVHDF 
application. In the future, randomized, controlled, double-blind, clinical trials can be planned to compare the changes in renal function and mortality rates of CVVHDF with longer or repeated administration.

\section{Conclusions}

CVVHDF with Oxiris filter leads to a statistically significant decrease in NIR. Therefore, we think that the use of CVVHDF with Oxiris filter applied for septic shock-related AKI will save us time and increase the improvement.

\section{Declarations}

1.Ethics committee: Republic of turkey, health sciences university, Gazi Yaşargil training and research hospital Ethics committee for clinical research

Consent to participate: We obtained written informed consent from each first degree relative of patient.

2.Consent for publication: Not Applicable

3.Availability of data and materials: The datasets used and/or analysed during the current study available from the corresponding author on reasonable request. (akyektas@hotmail.com)

4.Competing interests: The authors declare no competing interests.

5.Funding: Not funding

\section{Author contribution:}

AKY, OU and CKK carried out the anterior and posterior sciatic nerve block, participated in the sequence alignment and drafted the manuscript, participated in the design of the study and performed the statistical analysis. DK and EY conceived of the study, and participated in its design and coordination and helped to draft the manuscript. All authors read and approved the final manuscript.

7.Acknowledgements: Not Applicable

\section{References}

1. Singer M, Deutschman CS, Seymour C, Shankar-Hari M, Annane D, Bauer M, et al. The third international consensus definitions for sepsis and septic shock (sepsis-3). JAMA - J Am Med Assoc. 2016;315(8):801-10.

2. Grin PM, Dwivedi DJ, Chathely KM, Trigatti BL, Prat A, Seidah NG, et al. Low-density lipoprotein (LDL)dependent uptake of Gram-positive lipoteichoic acid and Gram-negative lipopolysaccharide occurs through LDL receptor. Sci Rep [Internet]. 2018;8(1):1-11. Available from:

http://dx.doi.org/10.1038/s41598-018-28777-0 
3. Chausse JM, Malekele L, Paruk F. Improved understanding of the pathophysiology of sepsis: Setting the scene for potential novel adjunctive therapies. South African J Crit Care. 2018;34(1):4-8.

4. Broman ME, Hansson F, Vincent JL, Bodelsson M. Endotoxin and cytokine reducing properties of the oXiris membrane in patients with septic shock: A randomized crossover double-blind study. PLoS One. 2019;14(8).

5. Nusshag $\mathrm{C}$, Weigand MA, Zeier M, Morath $C$, Brenner T. Issues of acute kidney injury staging and management in sepsis and critical illness: A narrative review. Vol. 18, International Journal of Molecular Sciences. MDPI AG; 2017.

6. Rhodes A, Evans LE, Alhazzani W, Levy MM, Antonelli M, Ferrer R, et al. Surviving Sepsis Campaign: International Guidelines for Management of Sepsis and Septic Shock: 2016. Intensive Care Med. 2017 Mar 1;43(3):304-77.

7. Dellinger RP, Bagshaw SM, Antonelli M, Foster DM, Klein DJ, Marshall JC, et al. Effect of Targeted Polymyxin B Hemoperfusion on 28-Day Mortality in Patients with Septic Shock and Elevated Endotoxin Level: The EUPHRATES Randomized Clinical Trial. JAMA - J Am Med Assoc. 2018 Oct 9;320(14):1455-63.

8. Schädler D, Pausch C, Heise D, Meier-Hellmann A, Brederlau J, Weiler N, et al. The effect of a novel extracorporeal cytokine hemoadsorption device on IL -6 elimination in septic patients: A randomized controlled trial. PLoS One. 2017 Oct 1;12(10).

9. Broman ME, Bodelsson M. Analysis of endotoxin adsorption in two swedish patients with septic shock. Blood Purif. 2019;47(Suppl3):51-3.

10. Zhang J, Tian J, Sun H, Digvijay K, Neri M, Bhargava V, et al. How does continuous renal replacement therapy affect septic acute kidney injury? Vol. 46, Blood Purification. S. Karger AG; 2018. p. 326-31.

11. Honore PM, Spapen HD. What a clinician should know about a renal replacement membrane? J Transl Intern Med. 2018 Jun 28;6(2):62-5.

12. Hattori N, Oda S. Cytokine-adsorbing hemofilter: old but new modality for septic acute kidney injury. Ren Replace Ther [Internet]. 2016 Dec 18 [cited 2019 Dec 6];2(1):41. Available from: http://rrtjournal.biomedcentral.com/articles/10.1186/s41100-016-0051-1

13. Schwindenhammer V, Girardot T, Chaulier K, Grégoire A, Monard C, Huriaux L, et al. Oxiris ${ }^{\circledR}$ use in septic shock: Experience of two French centres. Blood Purif. 2019 Apr 1;47(Suppl3):29-35.

14. Monard C, Rimmelé T, Ronco C. Extracorporeal Blood Purification Therapies for Sepsis. Blood Purif [Internet]. 2019 [cited 2019 Dec 6];47(3):2-15. Available from: www.karger.com/bpu

15. KDIGO Clinical Practice Guideline for Acute Kidney Injury. Off J Int Soc Nephrol [Internet]. 2012 [cited 2019 Dec 6];2(1). Available from: http://www.kidney-international.org

16. Preau S, Bortolotti P, Colling D, Dewavrin F, Colas V, Voisin B, et al. Diagnostic Accuracy of the Inferior Vena Cava Collapsibility to Predict Fluid Responsiveness in Spontaneously Breathing Patients With Sepsis and Acute Circulatory Failure. Crit Care Med. 2017 Mar;45(3):e290-e297.

17. Laurent Muller, Xavier Bobbia, Mehdi Toumi, Guillaume Louart, Nicolas Molinari, Benoit Ragonnet, et al. Respiratory variations of inferior vena cava diameter to predict fluid responsiveness in 
spontaneously breathing patients with acute circulatory failure: need for a cautious use. Crit Care. 2012 Oct 8;16(5):R188.

18. Finney SJ, Leaver SK, Evans TW, Burke-Gaffney A. Differences in lipopolysaccharide- and lipoteichoic acid-induced cytokine/chemokine expression. Intensive Care Med [Internet]. 2012 Feb 20 [cited 2019 Dec 6];38(2):324-32. Available from: http://link.springer.com/10.1007/s00134-011-2444-5

19. Poston JT, Koyner JL. Sepsis associated acute kidney injury. Vol. 364, BMJ (Online). BMJ Publishing Group; 2019.

20. Peerapornratana S, Manrique-Caballero CL, Gómez H, Kellum JA. Acute kidney injury from sepsis: current concepts, epidemiology, pathophysiology, prevention and treatment. Vol. 96, Kidney International. Elsevier B. V.; 2019. p. 1083-99.

21. Xu Z, Cheng B, Fu S, Liu X, Xie G, Li Z, et al. Coagulative biomarkers on admission to the ICU predict acute kidney injury and mortality in patients with septic shock caused by intra-abdominal infection. Infect Drug Resist. 2019;12:2755-64.

22. Kumar A, Zarychanski R, Light B, Parrillo J, Maki D, Simon D, et al. Early combination antibiotic therapy yields improved survival compared with monotherapy in septic shock: A propensity-matched analysis. Crit Care Med. 2010;38(9):1773-85.

23. Angus DC, Linde-Zwirble WT, Lidicker J, Clermont G, Carcillo J, Pinsky MR. Epidemiology of severe sepsis in the United States: Analysis of incidence, outcome, and associated costs of care. Crit Care Med. 2001;29(7):1303-10.

24. Vincent JL, Sakr Y, Sprung CL, Ranieri VM, Reinhart K, Gerlach H, et al. Sepsis in European intensive care units: Results of the SOAP study. Crit Care Med. 2006;34(2):344-53.

25. Vincent JL, Rello J, Marshall J, Silva E, Anzueto A, Martin CD, et al. International study of the prevalence and outcomes of infection in intensive care units. JAMA - J Am Med Assoc. 2009 Dec 2;302(21):2323-9.

26. Martin GS, Mannino DM, Eaton S, Moss M. The epidemiology of sepsis in the United States from 1979 through 2000. N Engl J Med. 2003 Apr 17;348(16):1546-54.

27. Vincent JL, Marshall JC, Ñamendys-Silva SA, François B, Martin-Loeches I, Lipman J, et al. Assessment of the worldwide burden of critical illness: The Intensive Care Over Nations (ICON) audit. Lancet Respir Med. 2014 May 1;2(5):380-6.

28. Artero A, Zaragoza R, Miguel J. Epidemiology of Severe Sepsis and Septic Shock. Sev Sepsis Septic Shock - Underst a Serious Kill. 2012;(June):2-24.

29. Malard B, Lambert C, Kellum JA. In vitro comparison of the adsorption of inflammatory mediators by blood purification devices. Intensive Care Med Exp. 2018 Dec;6(1).

30. Shum HP, Chan KC, Kwan MC, Yan WW. Application of endotoxin and cytokine adsorption haemofilter in septic acute kidney injury due to Gram-negative bacterial infection. Hong Kong Med J. 2013 Dec;19(6):491-7.

31. Turani F, Barchetta R, Falco M, Busatti S, Weltert L. Continuous renal replacement therapy with the adsorbing filter oxiris in septic patients: A case series. Blood Purif. 2019 Apr 1;47(Suppl3):54-8. 
32. Dahaba AA, Elawady GA, Rehak PH, List WF. Procalcitonin and proinflammatory cytokine clearance during continuous venovenous haemofiltration in septic patients. Anaesth Intensive Care [Internet]. 2002 Jun [cited 2019 Dec 6];30(3):269-74. Available from:

http://www.ncbi.nlm.nih.gov/pubmed/12075632

33. Samsudin I, Vasikaran SD, Vasikaran S. Clinical Utility and Measurement of Procalcitonin. I Clin Biochem Rev. 2017;38(2):59-68.

\section{Tables}

Table 1: Source of sepsis, blood culture growth and filter type data of the study patients 


\begin{tabular}{|c|c|c|c|c|}
\hline Study Patient & Source of sepsis & Bacterial Growth in Blood & Gram & Filter \\
\hline 1 & Urinary tract & K. pneumoniae & - & AN69 \\
\hline 2 & Lungs & S. epidermidis & + & AN69 \\
\hline 3 & Soft tissue & P. aeruginosa & - & AN69 \\
\hline 4 & Soft tissue & S. epidermidis & + & Oxiris \\
\hline 5 & Urinary tract & A. baumannii & - & AN69 \\
\hline 6 & Lungs & S. hominis ssp hominis & + & Oxiris \\
\hline 7 & Catheter-related & S. hominis ssp hominis & + & Oxiris \\
\hline 8 & Catheter-related & E. faecium & + & AN69 \\
\hline 9 & Catheter-related & S. aureus & + & AN69 \\
\hline 10 & Lungs & A. baumannii & - & Oxiris \\
\hline 11 & Abdomen & Enterobacter spp. & - & Oxiris \\
\hline 12 & Lungs & P. aeruginosa & - & AN69 \\
\hline 13 & Lungs & S. aureus & + & Oxiris \\
\hline 14 & Catheter-related & S. haemolyticus & + & AN69 \\
\hline 15 & Unclear & Unclear & Unclear & AN69 \\
\hline 16 & Abdomen & Enterobacter spp. & - & AN69 \\
\hline 17 & Soft tissue & P. aeruginosa & - & AN69 \\
\hline 18 & Catheter-related & S. hominis ssp hominis & + & Oxiris \\
\hline 19 & Unclear & Unclear & Unclear & Oxiris \\
\hline 20 & Abdomen & A. baumannii & & Oxiris \\
\hline 21 & Unclear & Unclear & Unclear & AN69 \\
\hline 22 & Lungs & A. baumannii & - & AN69 \\
\hline 23 & Lungs & P. aeruginosa & - & AN69 \\
\hline 24 & Lungs & P. aeruginosa & - & AN69 \\
\hline 25 & Lungs & K. pneumoniae & - & Oxiris \\
\hline 26 & Soft tissue & S. maltophilia & - & Oxiris \\
\hline 27 & Urinary tract & A. baumannii & - & Oxiris \\
\hline 28 & Unclear & Unclear & Unclear & AN69 \\
\hline 29 & Unclear & Unclear & Unclear & AN69 \\
\hline 30 & Lungs & A. baumannii & - & AN69 \\
\hline 31 & Lungs & A. baumannii & - & Oxiris \\
\hline 32 & Unclear & Unclear & Unclear & Oxiris \\
\hline 33 & Abdomen & M. R. S. aureus & + & AN69 \\
\hline 34 & Urinary tract & E. coli & - & Oxiris \\
\hline 35 & Abdomen & Enterobacter spp. & - & Oxiris \\
\hline 36 & Lungs & S. aureus & 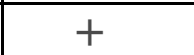 & Oxiris \\
\hline 37 & Unclear & Unclear & Unclear & Oxiris \\
\hline 38 & Soft tissue & P. aeruginosa & - & Oxiris \\
\hline 39 & Lungs & K. pneumoniae & - & AN69 \\
\hline 40 & Soft tissue & S. epidermidis & + & AN69 \\
\hline 41 & $\begin{array}{l}\text { Lungs } \\
\end{array}$ & K. pneumoniae & - & Oxiris \\
\hline 42 & Soft tissue & P. aeruginosa & - & Oxiris \\
\hline
\end{tabular}


Table 2. Comparison of groups in terms of blood culture result

\begin{tabular}{llll}
\hline Blood culture result & Grup 1 n (\%) & Grup 2 n (\%) & p value* \\
\hline Gram (-) & $12(57,1)$ & $11(52,4)$ & 0,911 \\
Gram (+) & $6(28,6)$ & $6(28,6)$ & \\
Unclear & $3(14,3)$ & $4(19)$ & \\
\hline Total & $21(100)$ & $21(100)$ & \\
\hline
\end{tabular}

*: Chi square $\mathrm{p}$ value

Table 3. Comparison of clinical features of the groups

\begin{tabular}{|c|c|c|c|}
\hline & $\begin{array}{l}\text { Group1 }(\mathrm{n}=21) \\
\text { (Mean } \pm \text { SD) }\end{array}$ & $\begin{array}{l}\text { Group } 2(n=21) \\
\text { (Mean } \pm \text { SD) }\end{array}$ & pvalue $^{e ́}$ \\
\hline Age (Year) & $59.71 \pm 20.14$ & $62.95 \pm 20.24$ & 0.6 \\
\hline APACHE II score & $29.52 \pm 7.84$ & $29 \pm 7.84$ & 0.83 \\
\hline Number of organ failers & $3.3 \pm 0.65$ & $3.19 \pm 0.6$ & $0.42^{\#}$ \\
\hline Mortality after AKI(day) & $17.21 \pm 21.1(\mathrm{n}=14)$ & $54.45 \pm 157.76(n=11)$ & 0.38 \\
\hline Length of stay in ICU(day) & $35.8 \pm 44.36$ & $71.14 \pm 136.85$ & 0.26 \\
\hline KDİGO Stage & $2.24 \pm 0.83$ & $2.38 \pm 0.74$ & 0.56 \\
\hline
\end{tabular}


Table 4. Comparison of pre- and post-CVVHDF clinical features and laboratory values of the groups

\begin{tabular}{|c|c|c|c|}
\hline & $\begin{array}{l}\text { Group1 }(n=21) \\
(\text { Mean } \pm \text { SD) }\end{array}$ & $\begin{array}{l}\text { Group } 2(n=21) \\
(\text { Mean } \pm \text { SD) }\end{array}$ & pvalue é \\
\hline SOFA score 1 & $10.01 \pm 2.73$ & $10.05 \pm 2.90$ & 0.95 \\
\hline SOFA score 2 & $10.19 \pm 2.8$ & $10.33 \pm 3.21$ & 0.87 \\
\hline pvalue* & 0.62 & 0.16 & \\
\hline Urea(mg/dl)1 & $92.52 \pm 38.42$ & $105.9 \pm 55.9$ & 0.37 \\
\hline Urea(mg/dl)2 & $82.9 \pm 34.36$ & $90.47 \pm 42.75$ & 0.53 \\
\hline pvalue* & 0.23 & 0.04 & \\
\hline Creatine(mg/dl)1 & $2.14 \pm 1.1$ & $2.61 \pm 1.53$ & 0.25 \\
\hline Creatine(mg/dl)2 & $1.89 \pm 0.96$ & $2.32 \pm 1.37$ & 0.25 \\
\hline pvalue* & 0.09 & 0.98 & \\
\hline $\mathrm{GFR}(\mathrm{ml} / \mathrm{dk} / 1.73 \mathrm{~m} 2) 1$ & $40.47 \pm 26.28$ & $31.61 \pm 22.13$ & 0.24 \\
\hline GFR(ml/dk/1.73 m2)2 & $44.42 \pm 26.43$ & $35.52 \pm 21.56$ & 0.23 \\
\hline pvalue* & 0.22 & 0.25 & \\
\hline Albumin(g/l)1 & $2.51 \pm 0.41$ & $2.69 \pm 0.29$ & 0.33 \\
\hline Albumin(g/l)2 & $2.51 \pm 0.41$ & $2.69 \pm 0.29$ & 0.13 \\
\hline pvalue* & 0.94 & 0.4 & \\
\hline Hemoglobin(g/dl)1 & $9.41 \pm 1.49$ & $8.66 \pm 1.26$ & 0.08 \\
\hline Hemoglobin(g/dl)2 & $9.43 \pm 1.33$ & $8.97 \pm 1.43$ & 0.29 \\
\hline pvalue* & 0.93 & 0.29 & \\
\hline Hematocrit(\%)1 & $29.72 \pm 4.23$ & $28 \pm 4.06$ & 0.18 \\
\hline Hematocrit(\%)2 & $29.87 \pm 3.61$ & $29.33 \pm 4.1$ & 0.65 \\
\hline pvalue* & 0.84 & 0.08 & \\
\hline Platelet $\left(10^{3} / \mu \mathrm{L}\right) 1$ & $175.14 \pm 98.42$ & $222.47 \pm 130.76$ & 0.19 \\
\hline Platelet $\left(10^{3} / \mu \mathrm{L}\right) 2$ & $174.14 \pm 104.85$ & $187 \pm 129.18$ & 0.72 \\
\hline pvalue* & 0.92 & 0.02 & \\
\hline Lactate $(\mathrm{mmol} / \mathrm{l}) 1$ & $2.56 \pm 1.90$ & $2.49 \pm 2.82$ & $0.4^{\#}$ \\
\hline Lactate(mmol/l) 2 & $2.07 \pm 1.1$ & $2.25 \pm 2.11$ & $0.58^{\#}$ \\
\hline pvalue* & 0.07 & 0.49 & \\
\hline $\mathrm{WBC}\left(10^{3} / \mu \mathrm{L}\right) 1$ & $17.12 \pm 6.06$ & $17.69 \pm 8.66$ & 0.8 \\
\hline $\mathrm{WBC}\left(10^{3} / \mu \mathrm{L}\right) 2$ & $18.41 \pm 7.81$ & $16.53 \pm 9.31$ & 0.48 \\
\hline pvalue* & 0.31 & 0.26 & \\
\hline $\mathrm{CRP}(\mathrm{mg} / \mathrm{l}) 1$ & $181.18 \pm 103.9$ & $178.61 \pm 108.24$ & 0.93 \\
\hline $\mathrm{CRP}(\mathrm{mg} / \mathrm{l}) 2$ & $159.74 \pm 80.85$ & $166,48 \pm 106.55$ & 0.81 \\
\hline pvalue* & 0.15 & 0.44 & \\
\hline $\operatorname{ESR}(\mathrm{mm} / \mathrm{h}) 1$ & $43.52 \pm 27.78$ & $48.47 \pm 34.26$ & 0.61 \\
\hline $\operatorname{ESR}(\mathrm{mm} / \mathrm{h}) 2$ & $43.09 \pm 23.07$ & $44.47 \pm 30.77$ & 0.87 \\
\hline pvalue* & 0.85 & 0.43 & \\
\hline Procalcitonin(ng/ml)1 & $13.55 \pm 19.93$ & $21.56 \pm 36.25$ & $0.77^{\#}$ \\
\hline Procalcitonin(ng/ml)2 & $11.28 \pm 16.13$ & $16.56 \pm 26.9$ & $0.95^{\#}$ \\
\hline pvalue* & 0.04 & $0.002^{\mathcal{E}}$ & \\
\hline NİR(mcg / kg/ min)1 & $0.53 \pm 0.18$ & $0.37 \pm 0.2$ & 0.08 \\
\hline $\operatorname{Nİ}(\mathrm{mcg} / \mathrm{kg} / \mathrm{min}) 2$ & $0.42 \pm 0.23$ & $0.39 \pm 0.22$ & 0.8 \\
\hline
\end{tabular}


APACHE: Acute Physiology and Chronic Health Evaluation; SOFA: Sequential Organ Failure Assessment; AKI: Acute Kidney İnjury; ICU: Intensive Care Unit; KDİGO: Kidney Disease Improving Global Outcomes; GFR:

Glomerular filtration rate; WBC: White blood cell; CRP: C-reactive protein; ESR: Erythrocyte sedimentation rate; NİR: Noradrenaline infusion rate; é: Student-t $\mathrm{p}$ value; \#: Mann Whitney U test $\mathrm{p}$ value; *: Pairedsamples t-test $\mathrm{p}$ value, \&: Wilcoxon test pvalue, 1: Pre-dialysis; 2: Post-dialysis

Table 5. Comparison of groups in terms of gender, mortality and anticoagulants

\begin{tabular}{cllc}
\hline & Group 1 n (\%) & Group 2 n (\%) & pvalue* \\
\hline Gender & & & \\
\hline Female & $10(47.6)$ & $11(52.4)$ & 0.75 \\
$\quad$ Male & $11(52.4)$ & $10(47.6)$ & \\
Mortality & & & 0.34 \\
$(-)$ & $7(33.3)$ & $10(47.6)$ & \\
$(+)$ & $14(66.7)$ & $11(52.4)$ & 1 \\
Anticoagulant & & & \\
$\quad$ Heparin & $17(81)$ & $17(81)$ & \\
Citrate & $4(19)$ & $4(19)$ & \\
\hline Total & $21(100)$ & $21(100)$ & \\
\hline
\end{tabular}

*: Chi squarep value

\section{Figures}

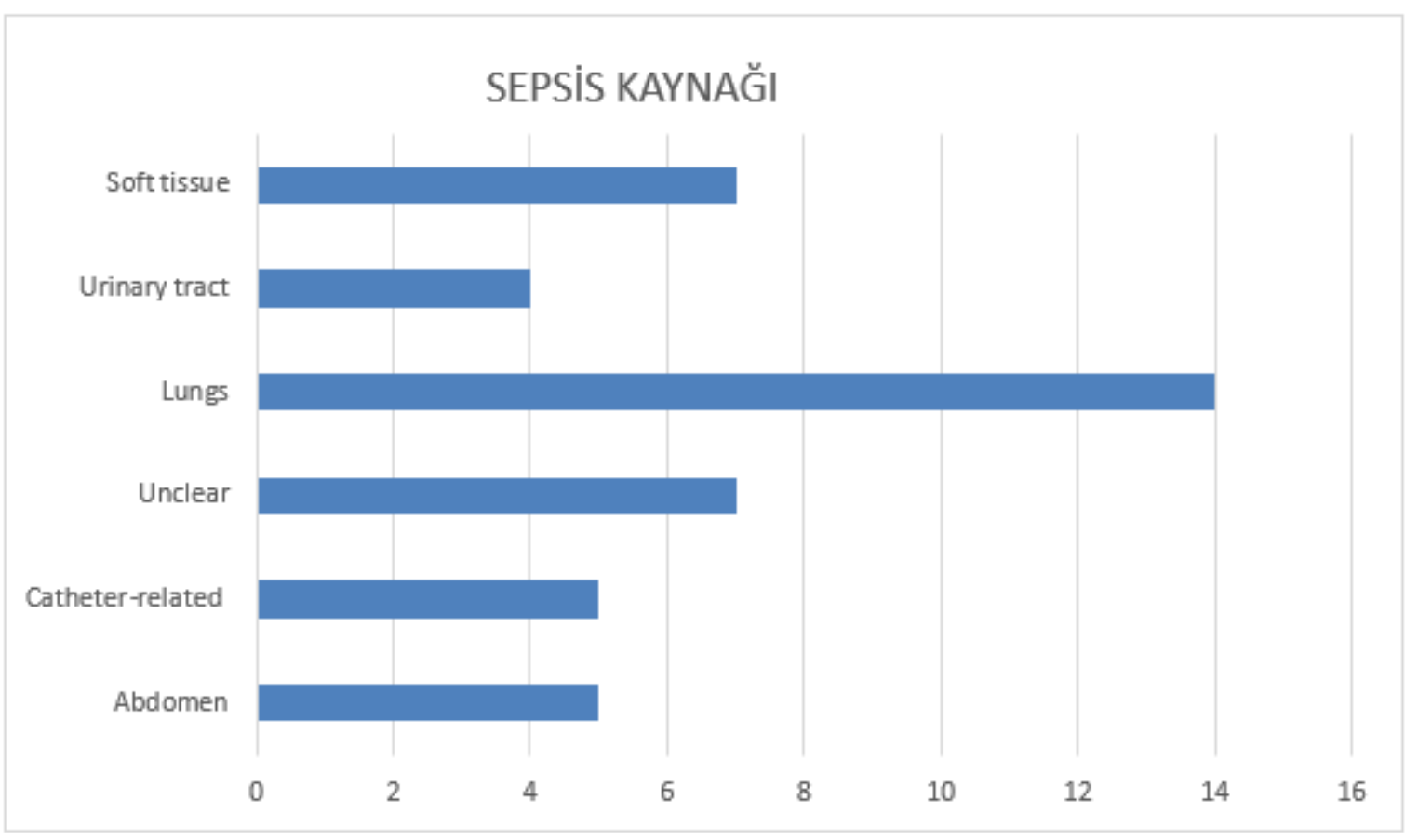




\section{Figure 1}

Classification of patients in terms of the source of sepsis 